\title{
A EDUCAÇÃO EM MUDANÇAS CLIMÁTICAS: UMA ABORDAGEM INTERDISCIPLINAR
}

\author{
C. M. L. FERNANDES SILVA ${ }^{1 *}$, F. A. COSTA ${ }^{2}$ e G. L. BORBA ${ }^{2}$ \\ ${ }^{1}$ Instituto Federal de Educação, Ciência e Tecnologia do Rio Grande do Norte \\ ${ }^{2}$ Universidade Federal do Rio Grande do Norte \\ carlos.fernandes@ifrn.edu.br*
}

Artigo submetido em janeiro/2016 e aceito em maio/2016

DOI: $10.15628 /$ holos.2016.3950

\section{RESUMO}

Relatórios oficiais sugerem que as emissões de gases de efeito estufa produzidos pelas atividades humanas contribuem para acelerar as mudanças climáticas. As emissões são geradas, em grande parte, para atender o consumismo praticado pela sociedade contemporânea. Esse consumismo reflete a pouca valorização da dimensão ambiental e interdisciplinar na educação fornecida à sociedade. Pesquisas indicam que as causas e efeitos das mudanças climáticas podem ser atenuados pela prática de uma educação específica nessa área, somada a pedagogias interdisciplinares voltadas ao meio ambiente e à sustentabilidade. O estudo da eficiência de uma educação interdisciplinar em mudanças climáticas, com vistas a uma alteração do comportamento e das atividades antrópicas, ainda é incipiente e pouco aplicado no mundo, entretanto é bastante relevante para o contexto atual. $\mathrm{O}$ artigo aborda questões sobre os efeitos da aplicação de uma educação em mudanças climáticas de forma interdisciplinar, na mitigação da emissão dos gases de efeito estufa e na adaptação as mudanças climáticas.

PALAVRAS-CHAVE: Educação em Mudanças Climáticas, Interdisciplinaridade, Sustentabilidade.

\section{EDUCATION ON CLIMATE CHANGE: AN INTERDISCIPLINARY APPROACH}

\section{ABSTRACT}

Official reports suggest that the greenhouse gas emissions produced by human activities contribute to accelerating climate change. The emissions are generated, largely to meet the consumption practiced by contemporary society. This consumption reflects the low valuation of environmental dimension and interdisciplinary in education provided to society. Research indicates that the causes and effects of climate change can be mitigated by the practice of a specific education in this area, coupled with pedagogies interdisciplinary related to the environment and sustainability. The study of the efficiency of an interdisciplinary education on climate change with a view to a change of behavior and human activities, is still incipient and little applied in the world, though it is quite relevant to the current context. The article addresses questions about the effects of the application of an education on climate change in an interdisciplinary way in mitigating the emission of greenhouse gases and adapting to climate change.

KEYWORDS: Education on climate changing, Interdisciplinary, Sustainability. 


\section{INTRODUÇÃO}

As mudanças climáticas estão entre os principais temas da política mundial, uma vez que seus efeitos afetam a humanidade nos contextos social, ambiental, cultural e econômico. Os processos relacionados ao comportamento do clima são caracterizados por interdisciplinaridade, complexidade e incerteza. Diante disso, a sua compreensão requer conhecimentos de diversas áreas, tais como: componentes climáticos, biofísicos, ambientais, geográficos, químicos, físicos entre outros. Além disso, as causas e efeitos das mudanças climáticas interligam o passado, o presente e o futuro da história da humanidade, interferindo na vida humana nos níveis pessoal e global (UNESCO, 2014a).

O clima é um dos elementos do meio ambiente, e sua alteração em nível global pode ser causada de forma natural por diversos eventos, mas particularmente por vulcanismo, atividade solar e quedas de grandes meteoros. Entretanto, pesquisas vêm apontando há décadas que as atividades humanas nos dois séculos anteriores mudaram fortemente o meio ambiente e estão contribuindo para a aceleração das mudanças climáticas globais (IPCC, 2014; CBD, 2014). Mesmo não sendo um consenso científico (MARUYANA, 2009; MOLION, 2008), estudos indicam que atividades antrópicas estão provocando alterações na composição da atmosfera e consequente aumento da temperatura média global, o que resultará em um aumento do número de eventos climáticos extremos, tais como furacões e enchentes mais intensas, secas mais prolongadas e escassez de recursos hídricos em diversas regiões do planeta (IPCC, 2014; IPEA, 2011).

A atividade antrópica, em seus elevados níveis, dita o ritmo do consumo dos recursos da natureza. Quando guiada pelas diretrizes do modelo desenvolvimentista, constrói uma sociedade com um olhar quase que unilateral para a dimensão econômica do desenvolvimento. Essa visão deficiente da sociedade propiciou, no século anterior, a instauração em seu seio de uma norma social depredadora do meio ambiente - o consumismo (ASSADOURIAN, 2010). O excesso de consumo de bens e serviços está vinculado à ausência de uma consciência ambiental, uma vez que o desenvolvimentismo incentiva o consumo do desnecessário, minando os recursos naturais da Terra e transformando-os, em parte, na emissão de Gases de Efeito Estufa (GEE). Tais emissões são hoje um dos principais fatores que contribuem para a aceleração das mudanças climáticas (IPCC, 2014).

As atividades antrópicas, fonte dessas emissões, possuem uma relação com o nível e o foco de educação exercida pela sociedade, pois apesar de serem necessárias à sobrevivência, estão impregnadas por cultura, valores e comportamento (ASSADOURIAN, 2010; MOCHIZOKI, 2015). Dessa forma, a ausência da dimensão ambiental na cultura consumista tem indicado que grande parte do sistema educacional atual não forma para a preservação da biodiversidade, a cooperação ambiental e a sustentabilidade. Diversas linhas educacionais têm abordado esses temas educação ambiental, educação para a sustentabilidade e educação para o desenvolvimento sustentável - de forma direta e indireta.

A Educação em Mudanças Climáticas (EMC) - Climate Change Education (CCE) - é uma nova proposta que possui suas bases nas educações citadas anteriormente, mas ainda não conta 
com um referencial próprio definido ${ }^{1}$. A EMC possui diretrizes iniciais que apontam para a necessidade de se aperfeiçoar a alfabetização sustentável ${ }^{2}$ e climática da população, com a meta de atenuar o consumismo e, assim, não só mitigar as causas e efeitos das mudanças climáticas, mas também melhorar a adaptação a elas. De uma forma geral a EMC almeja conseguir melhorar a compreensão da dinâmica entre as atividades antrópicas e as mudanças climáticas, promovendo a conscientização sobre a relevância da execução dos processos de mitigação e da adaptação aos seus efeitos (LAESSфE et al., 2009; BANGAY; BLUN, 2008).

Este artigo busca analisar como a interdisciplinaridade e a EMC - com o foco na dimensão ambiental do desenvolvimento sustentável - , podem facilitar a construção de processos de mitigação e adaptação para as mudanças climáticas. Essa análise se mostra importante para o contexto socioambiental, uma vez que discussões sobre os efeitos da educação na problemática das mudanças climáticas ainda são incipientes. As ideias aqui examinadas tanto podem trazer um aumento de consciência ambiental, como também gerar outros vieses de estudo do tema discutido no presente trabalho.

\section{A NECESSIDADE DA DIMENSÃO CLIMOAMBIENTAL NA EDUCAÇÃO}

Boa parte da estrutura educacional atual não atende $\mathrm{e}^{3}$ aos anseios da dimensão ambiental, que requer conceitos como cooperação, solidariedade, bom uso da natureza, formação cidadã plena e efetiva. Ao priorizar excessivamente a formação para o cientificismo tecnológico, deixando as questões humanas de ética e política ambientais em segundo plano, o sistema educacional se pauta em instruir sociedades consumistas (ASSADOURIAN, 2010; LIMA, 2013). Mesmo com algumas tentativas da educação em ensinar noções de sustentabilidade e ecologia em temas transversais, a instrução para o consumo ainda é preponderante. Em regra o que se faz é uma educação circunscrita à competição de mercado e à formação técnica científica, onde muitas vezes se incentiva o consumo irrefletido - consumo do supérfluo, do que já se tem, do que não se faz uso, entre outros exemplos - e nessa educação, a ideia ilusória de que a dimensão econômica é o sustentáculo da sociedade é construída e ensinada como uma verdade. A educação deve ser abrangente e interdisciplinar, porém ao priorizar uma só dimensão da sustentabilidade - a econômica - negligencia-se as necessidades dos setores social, cultural, ambiental e climático, entre outras demandas inerentes à condição humana (SOBRAL, 2000; CORREIA et al., 2010).

O ônus de se educar unidimensionalmente, com base numa racionalidade econômica e por meio da especificidade de conteúdo, aprofundando particularidades, é pago com a fragilização da universalidade do conhecimento e o aleijamento da formação de uma cidadania global. Essa alienação do setor econômico pode ser vista através dos efeitos da formação tecnicista, aliada à falta de noções de educação ambiental ou sustentável. Portanto, a busca pela formação de um cidadão crítico em seus atos muitas vezes torna-se vã, pois processos ambientais, climáticos e antrópicos exigem a interdisciplinaridade do conhecimento alicerçada numa racionalidade ambiental (LEFF, 2006). Efetivamente esse tipo de formação, desprovida dessas dimensões

\footnotetext{
${ }^{1}$ Recentemente trabalhos apontam para a Educação em Mudanças Climáticas no Desenvolvimento Sustentável (EMCDS). Climate Change Education for Sustainable Development (CCESD).

${ }^{2}$ Alfabetização sustentável é ensinar ao maior número de pessoas possível princípios básicos de sustentabilidade.

${ }^{3} \mathrm{O}$ modelo educacional das últimas décadas tem priorizado a formação técnica, científica e competitiva para atender o modelo atual de produção e consumo.
} 
educacionais, contribui para o aumento de uma tecnologia direcionada a extrair ininterruptamente os recursos naturais a uma velocidade cada vez maior, com o objetivo de atender a demandas de crescente consumo. Como resultado dessa formação consumista ambientalmente insustentável, a sociedade inverte os valores passando a viver para produzir e consumir, alienando-se numa forma de vida que a impede de enxergar os perigosos efeitos das mudanças climáticas em andamento (ALMEIDA, 1997).

Um modelo educacional com essa diretriz não desperta a consciência de que os problemas das mudanças globais do clima estão conectados como um todo indissociável, sistêmico e orgânico que contém, também, as ações antrópicas ligadas à exploração excessiva do meio ambiente. Os resultados da falta de consciência ecológica na formação das pessoas sugerem a existência de uma lacuna a ser preenchida na área educacional: a inserção diferenciada da interdisciplinaridade ambiental, contendo um amplo debate sobre o aspecto climático (AMARAL, 2007).

Nesse amplo debate está a contribuição da EMC. Mesmo sendo uma educação que ainda busca assentar seus pilares e encontrar uma identidade definida (JACOBI et al., 2011) para se consolidar, a EMC pede uma mudança nas estruturas educacionais que vá além dos tradicionais pedidos de alterações de currículo e inserção de novos conteúdos, pois a sua prática requer uma reorganização na hierarquia das dimensões do desenvolvimento sustentável. Nesse sentido, os educadores devem promover culturas ensinando aos alunos que são os ecossistemas os mantenedores da dinâmica do planeta, e somente com o planeta saudável é que se pode conseguir estabilidade social e econômica (WWF, 2014).

A prioridade da dimensão climoambiental é evidente, uma vez que suas mudanças climáticas de média intensidade já podem causar transtornos social e econômico consideráveis. Diversos relatórios fornecem cenários sobre as consequências das mudanças climáticas, e nesses relatórios a educação é citada como instrumento relevante no combate as suas causas e aos seus efeitos (IPCC, 2014; IPEA, 2011; STERN, 2007). Nesse sentido, urge a necessidade de os decisores políticos melhorarem a compreensão dos efeitos sistêmicos das mudanças climáticas e fornecerem um maior suporte à educação, para que esta possa trazer respostas mais eficientes (MOCHIZOKI, 2015, FERNANDESSILVA, 2015).

\subsection{Os caminhos de uma educação para as mudanças climáticas}

O estudo das atividades humanas e sua influência nas mudanças climáticas, bem como dos procedimentos para enfrentar suas causas e efeitos, já foi objeto de reflexão na educação. Nas últimas décadas diversos trabalhos sobre essa temática foram produzidos, podendo ser encontrados na área de educação ambiental e em outras disciplinas ligadas à sustentabilidade (LIMA, 2013; GADOTTI, 2008). Por enquanto, a EMC ainda não conseguiu emergir como uma educação independente, e usa parte do referencial teórico da educação ambiental ou da educação para o desenvolvimento sustentável (EDS) para delinear seus objetivos (LAESSфE et al., 2009). Na primeira década deste século, a EMC inserida nessas educações desenvolveu abordagens próprias que analisam a influência do elemento educacional nas mudanças climáticas e em áreas afins, como na degradação ambiental. Essas abordagens podem ser realizadas por três caminhos paralelos e simultâneos que possuem objetivos comuns: a obtenção de conhecimento apropriado, as habilidades sobre as mudanças climáticas e a mudança nos padrões de atividade humana em busca de um comportamento mais sustentável (ANDERSON, 2010). 
O primeiro caminho da EMC quando integrada com a EDS é criar espaços de reflexão a respeito da importância das mudanças climáticas, construindo capacidades, atitudes sociais e individuais para fomentar mitigações aos seus efeitos. Os debates promovidos neste espaço de conscientização devem buscar reverter à inércia social perante as mudanças climáticas, uma vez que grande parte da comunidade mundial e até setores ligados diretamente ao clima têm ignorado o poder de influência da educação, que permite, entre outras coisas: mudar o comportamento das pessoas perante o exercício de mitigação, capacitá-las a se adaptarem às mudanças climáticas e levá-las a se engajarem no desenvolvimento sustentável (BANGAY; BLUN, 2008; ANDERSON, 2010).

Os educadores podem reforçar o engajamento da sociedade ensinando que o conhecimento, as habilidades e uma mudança comportamental contribuem na redução da emissão de GEE. Vale destacar que o engajamento e a prática desses ensinos só serão possíveis após a tomada de consciência de que as atividades antrópicas, além de influenciarem nas estruturas sociais e econômicas, estão intensificando as mudanças do clima. A aquisição dessa consciência e a certeza de que cada indivíduo pode contribuir na mitigação de GEE, exercendo uma vida mais sustentável, são metas importantes da EMC. Essas metas facilitam e incentivam ambientes de reflexão, criadores de iniciativas educacionais transformativas que vençam as barreiras ecológica, econômica, espacial, cultural, social, política e institucional (MOCHIZOKI, 2015).

No segundo caminho, a EMC pode desenvolver, através do processo de formação, capacidades, competências e atitudes visando à adaptação das pessoas aos impactos oriundos das mudanças do clima. Um dos objetivos centrais da adaptação é diminuir a vulnerabilidade das comunidades e aumentar a resistência aos choques ambientais, preparando as pessoas para um mundo mais populoso, com um novo padrão climático e provavelmente com menos recursos naturais (IPCC, 2014). Os benefícios da EMC na adaptação são múltiplos e podem ser explorados em vários aspectos para contribuir com a gestão ambiental, o desenvolvimento sustentável e a conscientização pública para o consumo. Outra vantagem é o desenvolvimento de políticas climáticas para a formação educacional vinculada a uma melhor adaptação às mudanças do clima e a um sistema de consumo e produção mais sustentável. Dessa forma, o fator educacional contribui para uma menor emissão de GEE, pois pessoas educadas podem se habituar ao consumo mais consciente ao mesmo tempo em que a educação técnica pode fomentar pesquisas sobre uma agricultura mais resistente e produtiva (ANDERSON, 2010).

Outras estratégias educacionais eficientes estão ligadas a uma adaptação às mudanças climáticas. A orientação educacional para redução de riscos de desastres é ponto estratégico que abre diversas opções, tais como planejamento de infraestrutura mais forte e melhor comunicação entre agentes governamentais, não governamentais e sociedade civil. Nesse aspecto, a evolução ainda é lenta, pois pesquisas indicam que existe uma falta de sintonia entre esses agentes e a agenda da redução de riscos de desastres ${ }^{4}$ (BLANKESPOOR et al., 2010).

Outra forma de a educação contribuir com a adaptação às mudanças climáticas é educando meninas e mulheres, uma vez que King e Mason (2001) indicam diversas literaturas sobre o poderoso efeito da educação feminina na comunidade, no capital social, na fertilidade e no bemestar geral de medidas tais como a expectativa de vida. A educação feminina torna as comunidades

4 O número de desastres registrados aumentou de ano a ano, de um total médio anual de 90 na década de 1970, para um valor próximo de 450 por ano na década de 2010 (WEBSTER, 2009). 
menos vulneráveis a eventos climáticos extremos, pois pesquisas apontam que sua implementação reduz a mortalidade e o número de feridos durante tragédias naturais, e isso inclui as tragédias climáticas (BLANKESPOOR et al., 2010).

Destaca-se que a educação para a adaptação não é exclusividade de uma educação feminina, de uma redução isolada da vulnerabilidade global, ou ainda, ganho desconectado de conhecimento para a preparação dos riscos das mudanças climáticas. A adaptação eficiente exige que essas abordagens, e outras, sejam feitas de forma paralela (ANDERSON, 2010).

O terceiro caminho da EMC consiste em estimular tanto a pesquisa sobre as causas e os efeitos das mudanças climáticas, como também a divulgação dos seus resultados para alertar as pessoas dos riscos dessas mudanças (UNESCO, 2014a). Em relação ao primeiro ponto, uma melhor qualidade em pesquisas interdisciplinares, nos processos que envolvem a problemática da mudança climática, aumenta a qualidade do conhecimento em diversos aspectos: mais certeza de quais as forças dominantes, quais os interesses econômicos envolvidos e a produção de relatórios mais confiáveis. Dessa forma, o entendimento mais claro desses aspectos melhora o nível de prontidão a respeito da realidade climática e diminui o descaso com que é tratada essa problemática pela população em geral. Segundo Hillman et al. (2007), esse estado de alerta irá minimizar a influência dos interesses anticlima e a propaganda de negação que circula a respeito dos perigos causados por mudanças climáticas significativas.

A aquisição e divulgação do conhecimento a respeito dos processos relacionados às mudanças climáticas e que são mediados pela EMC criam condições favoráveis para desenvolver adaptações e mitigações eficientes. São inúmeros os campos de abordagem da EMC nesse aspecto: o uso da relação entre a educação ambiental, alfabetização científica e mudança climática; mudança curricular formal e não formal; a história da mudança climática e sua relação com o modelo social; o conhecimento melhorado dos eventos climáticos, modelos de consumo, incertezas e estatísticas climáticas; o aproveitamento do seu caráter polêmico no ensino de ciências naturais; a análise de mitigações eficientes (MOCHIZOKI, 2015). Essas abordagens, entre outras, visam a aprendizagem de novos conhecimentos e habilidades e a mudança de comportamentos, a fim de reduzir as vulnerabilidades e gerir os riscos das mudanças climáticas nos ambientes vivenciais. Com efeito, para conseguir a realização dos objetivos dos três caminhos apresentados, é necessária uma ampla reforma com alto investimento financeiro para o setor educacional.

Percorrer os três caminhos está condicionado a um autoexame transformativo, que crie condições de se fazer escolhas mais sustentável com um foco ecológico. Essa transformação é iniciada por processos de leitura sobre temas relacionados às mudanças climáticas, debates e atividades que foquem a mudança interna do indivíduo. Uma transformação que remeta a uma análise da nossa existência no planeta, para o planeta e com o planeta, isto é, pela reflexão profunda dos efeitos das relações antrópicas no meio ambiente. Com efeito, isso só será conseguido através de um processo educativo diferenciado que promova união e constância nos objetivos dos caminhos (UNESCO, 2014a; FERNANDESSILVA, 2015). Dessa forma, destaca-se a necessidade de que os três caminhos sejam interiorizados pelas pessoas, o que facilitará o engajamento contínuo e a reflexão sobre o debate das mudanças climáticas.

O comportamento reflexivo e engajado obtido por meio da educação favorece que as mitigações, a adaptação e o aumento de consciência minimizem as causas e efeitos das mudanças climáticas. Tais comportamentos - reflexivos e engajados - são obtidos quando os projetos 
educacionais transformadores são intencionalmente focados e delimitados. Esse poder de transformação da educação intencional é bem colocado por Jacobi et al (2009, p.70) "Dessa forma, o pensamento, a capacidade de reflexividade, de conhecer o mundo, de tomar decisões, fazer escolhas e transformar veem-se ampliados pelas intencionalidades dos processos educativos". Assim, os três caminhos descritos, quando acionados simultânea e intencionalmente numa área de engajamento reflexivo, resultarão na prática efetiva da EMC.

Para levar adiante uma transformação comportamental mediada pela EMC, e de acordo com os três caminhos apresentados, um passo relevante é a continuidade do processo de conscientização e envolvimento dos alunos frente às ameaças dos efeitos das mudanças do clima. Os processos incentivadores do engajamento podem ser realizados por reformas em programas de ensino que olhem com maior seriedade para as mudanças climáticas, introduzindo novas valorações e significados, em nível coletivo e pessoal. Alguns valores individuais e coletivos estão dispostos na Década da educação para o desenvolvimento sustentável (Deds), propondo uma reforma nas bases da educação que amplie a visão da sociedade e descortine os perigosos efeitos invisíveis das mudanças climáticas (UNESCO, 2005).

Com a transformação do comportamento, as pessoas em número cada vez maior disponibilizam-se mais para o desenvolvimento do conhecimento e para a aquisição de competências, empoderando-se e criando condições mais adequadas à mudança pretendida. A mudança comportamental pode trazer benefícios diversos, como a mitigação no consumo de energia, diminuição do desmatamento, ampliação de reflorestamento e redução da poluição. No campo mais subjetivo, promove um aumento da criticidade em relação ao modelo de desenvolvimento, aos padrões de cultura, à desigualdade social e aos sistemas de valores e suas relações causais com as emissões GEE (ANDERSON, 2010).

\section{ATIVIDADES INICIAIS DA EDUCAÇÃO INTERDISCIPLINAR EM MUDANÇAS CLIMÁTICAS: CURRÍCULOS, HABILIDADES E COMPETÊNCIAS}

Pelo exposto, a EMC tanto dá relevância ao comportamento do indivíduo na sociedade, como também às ações antrópicas locais indicando que ambas possuem consequências com implicações globais 5 . De acordo com Anderson (2010), uma forma de conscientizar os alunos dos perigos de emissões locais de GEE é aumentar a visibilidade do problema, responsabilizando proporcionalmente os emissores. Esse aumento de visibilidade estabelece uma melhor conexão com a realidade das mudanças climáticas, gerando um melhor entendimento, e isso propicia tanto a criação como a execução de ações mitigativas. O seguimento multiplicador desse processo de formação tanto gera o engajamento do público, incentivando bons exemplos, como incentiva um aumento de políticas climáticas que transformem as ações locais e regionais em ações nacionais e globais (MOCHIZOKI, 2015).

Para a EMC, as necessárias reformas educacionais precisam de alterações nos currículos escolares, com a inserção de tópicos das mudanças climáticas que gerem discussões coletivas em processos sociais mais amplos. Na construção desse novo currículo, o norteamento dos conceitos, os conhecimentos específicos e os conteúdos básicos devem abrir um campo propício para o ensino da problemática do clima de forma interdisciplinar. Elenca-se para esse contexto alguns

\footnotetext{
${ }^{5}$ Essa preocupação também está inserida da educação ambiental (MEADOWS, 1989).
} 
conteúdos relacionados às mudanças climáticas com características locais e de influência nacional, tais como controle maior do ciclo das cheias, conhecimento da biodiversidade e sua proteção e métodos agrícolas mais sustentáveis (UNESCO, 2012). A inserção curricular da temática da mudança climática aqui proposta poderia ser estendida a diversos outros tópicos, por exemplo: clima e suas mudanças; desmatamento com suas consequências e interesses econômicos; o ciclo da água e sua contaminação; desertificação e degradação dos solos; poluição do ar; acidez oceânica, entre outros. Tais aspectos podem ser trabalhados no ensino de ciências desenvolvendo os aspectos éticos, econômicos e ecológicos, na busca de gerar consciência e motivação para fomentar estratégias direcionadas a diminuir a pressão ambiental.

Entretanto, somente essa mudança curricular não é suficiente para mudar atitudes e comportamentos. Reitera-se que é preciso um maciço investimento na qualidade da educação, integrando saberes científicos, ambientais e tradicionais para minimizar as mudanças climáticas, ou seja, a mitigação e a adaptação das mudanças climáticas precisam estar inseridas enfaticamente dentro do processo educacional.

O programa curricular da EMC pode conter diversas sugestões de atividades didáticopedagógicas relevantes como temas: tratamento da gestão de água e resíduos; benefícios de uma economia de baixo carbono; comparação entre o desmatamento e o manejo florestal; diferenças entre certezas, incertezas, modelos, cenários, projeções e riscos dos efeitos das mudanças climáticas, entre outros. Pesquisadores apontam que essas abordagens devem ser desenvolvidas concomitantemente com a evolução histórica multifacetada das mudanças climáticas em contextos diversos - científico, econômico, ecológico, social e político - , como também os temas de segurança e desenvolvimento global, visualizando as opções das futuras gerações (CARAMELLO; STRIEDER, 2011). No entanto, no Brasil, tais temas são abordados nas escolas de forma esporádica e descontextualizados, ou numa visão reducionista.

$A E M C$, quando inserida dentro das diretrizes da EDS, sugere que os currículos também contenham a crítica ao atual consumo de energia fóssil e à possibilidade de mudança para uma matriz energética mais limpa. Este nível de criticidade requer uma pedagogia que desenvolva um comportamento reflexivo, um exame da prática diária de consumo do cidadão e uma análise do paradigma social como um todo: seu sistema econômico, estilo de vida e padrões de cultura; sua desigualdade social e seu comportamento beligerante; seu consumismo e qual a parcela de culpa de cada um para a emissão de GEE (MOCHIZOKI, 2015; GOWDY, 2008).

A proposta de uma EMC deve procurar inserir na maior quantidade de disciplinas possíveis uma abordagem interdisciplinar, debatida numa transversalidade constante nas áreas cognitivas e afetivas. Deste modo, tal proposta deve procurar conscientizar as pessoas da necessidade de programar ações para minimizar as causas e efeitos das mudanças climáticas. Nessa proposta, a transversalidade desse conteúdo deve focar o desenvolvimento de competências e habilidades representadas de diversas formas: ágil adaptação a novas situações, desenvolvimento da capacidade de inovar e disponibilidade para a transformação e o equilíbrio das emoções. Portanto, este processo educacional exige um ensino/aprendizagem participativo, uma prática democrática com gestão da informação sobre a complexidade e interdisciplinaridade das mudanças climáticas, e um pensamento crítico sobre suas causas e efeitos (LIMA; LAYRARGUES, 2014).

Nessa perspectiva, Anderson (2010) indica que o benefício da conscientização do cidadão e de sua contribuição na intensificação das mudanças climáticas pode despertá-lo para contribuir 
com soluções mitigadoras. Dentre algumas soluções de mitigação que estão alinhadas com as premissas de um desenvolvimento sustentável e sustentabilidade, a ECM pode ensinar:

a) a trabalhar a tecnologia para cidades limpas e humanas, no sentido da melhor qualidade de vida;

b) o desenvolvimento do pensamento crítico e de habilidades em resolver problemas gerados por mudanças rápidas com incertezas;

c) a dominar as informações na análise e sintetização, planejamento, gestão de competências e habilidades ao longo da vida.

As habilidades e competências para minimizar as causas e efeitos das mudanças do clima são empoderamentos alcançados por meio de uma alfabetização climática, capacitando o cidadão a um maior senso de aquisição, avaliação e utilização de seu consumo, além de auxiliá-lo a refletir sobre suas atividades no meio ambiente e no clima. Também se insere nessa capacitação uma análise com mais liberdade e propriedade das mensagens passadas pela mídia, mercado e setores ligados às mudanças climáticas (UNEP, 2010). Nesse aspecto estão contidos a expansão do agronegócio, o interesse da indústria do combustível fóssil e o messianismo catastrófico dos efeitos climáticos (LIMA; LAYRARGUES, 2014).

\subsection{Experiências da educação para mudanças climáticas}

As experiências realizadas com a EMC se desenvolvem no mundo, em grande parte, dentro das orientações da EDS. Em alguns países essas experiências se dão pela educação ambiental. Em Labrador e Terra Nova, províncias do Canadá, são feitos planejamentos de ações sobre as mudanças climáticas usando a EMC desde 2005. O Canadá é um exemplo em que as normativas e regras da EDS e da EMC não conseguem ser plenamente cumpridas, porque a componente cultural local tem forte influência no processo, uma vez que o sistema de ensino direcionado para as grandes comunidades conflita com a cultura dos aborígenes nas pequenas comunidades (NAZIR et al, 2009). Esse exemplo mostra que no exercício da EMC as questões culturais locais são relevantes e influenciam no engajamento dos indivíduos em praticar atos sustentáveis.

Recentemente no Nepal foi lançado um programa com o objetivo geral de fortalecer as capacidades dos decisores políticos, planejadores de modelos educacionais e instituições de formação de professores. A execução do programa se deu através dos centros comunitários de aprendizagem que integraram a EMC, a educação para a preparação de desastres, a educação não formal e a EDS no sistema de ensino. Em última análise, o programa visa aumentar a capacidade de adaptação e mitigação das populações vulneráveis às mudanças climáticas através da educação (UNESCO, 2014b).

A China inclui os conhecimentos específicos das mudanças climáticas na educação básica reforçando a formação de crianças e adolescentes (HAN, 2015). Na Europa a Dinamarca vem usando as estratégias da EDS para promover iniciativas específicas relativas a EMC. Outros países da Europa e a Austrália usaram também EDS para temas direcionados às mudanças climáticas (CHAMBERS, 2009).

No Brasil a discussão da mudança climática é trabalhada com mais qualidade dentro da educação ambiental, pois a EDS ainda está iniciando sua construção. No ensino médio da maioria das escolas brasileiras, o fenômeno das mudanças climáticas é tratado como um tema isolado e 
sem conexões com conhecimentos éticos e voltados à cidadania. Por vezes, é ensinado na disciplina de Biologia em temas como ecologia e biodiversidade, associado a variações do clima. No caso da Física, em geral o ensino se preocupa somente com a identificação de grandezas da termologia usadas em estudos de climatologia. No aspecto geral, as mudanças climáticas - um assunto vinculado ao meio ambiente - são abordadas como um tema transversal de forma esporádica nas disciplinas do núcleo comum ou em Geografia como eixo temático ( $\mathrm{PCN}+, 2002)$. Nos cursos técnicos da área ambiental o tema é aprofundado em disciplinas específicas, e nas outras áreas no nível de ensino médio a abordagem praticamente inexiste. Isso representa um quadro preocupante para um fenômeno que têm o poder de influenciar a humanidade em escala global.

A EMC e as outras educações ligadas ao debate das mudanças climáticas procuram respostas em longo, médio e curto prazo. Porém, estudos apontam que é no longo prazo que se consegue uma mudança educacional que forneça habilidades, competências e outros instrumentos para fazer frente a suas causas e aos seus efeitos (UNESCO, 2012). O sucesso dessa mudança educacional em prol de minimizar os efeitos das mudanças climáticas, além de exigir paciência pelo tempo de operacionalização, configura-se claramente como uma meta que requer um esforço colossal, precisando do apoio de todos.

\section{CONSIDERAÇÕES FINAIS}

A influência da educação é relevante para atenuar os efeitos das mudanças climáticas em andamento. Os exemplos desses efeitos são diversos: o aumento da temperatura média global e do número de eventos climáticos extremos; uma mudança da dinâmica de chuvas do planeta trazendo enchentes mais intensas e consequentes problemas de infraestrutura; secas mais prolongadas com escassez de recursos hídricos em diversas regiões do planeta. O processo educacional voltado ao debate da intensificação desses efeitos conscientiza o cidadão de que, para garantir a sustentabilidade por meio de mudanças nos padrões de consumo, será preciso fazer paralelamente grandes transformações, em diversos setores, do modelo usado pela sociedade. $O$ discurso ambiental interdisciplinar precisa ser inserido na educação com mais profundidade para que a dimensão climática seja abordada e reconhecida como importante. Nesse sentido, diversas educações com o foco no meio ambiente e na sustentabilidade formam uma grande área que fornece base para a EMC.

Os efeitos das mudanças climáticas são inexoráveis, restando ao ser humano buscar se adaptar aos cenários climáticos do futuro. Entretanto, existe a possibilidade desses efeitos serem minimizados com o aumento da compreensão e divulgação do conhecimento, formas de adaptação e o uso de mitigações eficientes. São esses os caminhos em que a EMC pode contribuir, auxiliando na transformação do cidadão, possibilitando criar espaços de reflexão sobre a dinâmica das mudanças climáticas. Isto pode ser feito aumentando o engajamento pelo processo de reflexão, buscando alterar os currículos, conteúdos e abordagens didáticas, construindo competências e habilidades para enfrentar as suas consequências.

De forma recorrente, como acontece em processos educacionais, as mudanças curriculares, abordagens e as estratégias para pretendidas pela EMC irão requerer um investimento maciço na educação e uma nova interpretação do uso do meio ambiente e do contexto climático. $O$ estudo conclui que apesar de tentativas pontuais a nível mundial sem uma aplicação no Brasil, a EMC 
apresenta uma boa proposta para iniciar um processo de conscientização sobre as mudanças climáticas. Em suma, o presente artigo procura mostrar a necessidade de pesquisas que resultem na implementação da EMC no Brasil, avaliando de forma quantitativa a eficiência de suas abordagens pedagógicas.

\section{REFERÊNCIAS}

1. ALMEIDA, J. P. A interdisciplinaridade na constituição do pensamento ecológico. Revista de História Regional. v. 2 , n. 2, p. 187-200. 1997. Disponível em: <http://www.dominiopublico .gov.br/download/texto/pg000021.pdf>. Acesso em: 28 out. 2015.

2. AMARAL, M. T. A dimensão ambiental na cultura educacional brasileira. Revista brasileira de Estudos pedagógicos. v. 88, n. 218, p.107-121. 2007. Disponível em: <http://www.rbep.inep. gov.br/index.php/RBEP/article/viewFile/10/10>. Acesso em: 21 set. 2015.

3. ANDERSON, A. Combating climate change through quality education. Washington: Brookings, 2010. 16 p.

4. ASSADOURIAN, E. The rise and fall of consumer. In: Starke, L.; Mastny, L. (Eds.), Transforming cultures: From consumerism to sustainability. New York: Norton \& Norton, 2010. p. 3-20.

5. BANGAY, C., BLUN, N. Education responses to climate change and quality: two parts of the same agenda? International Journal of Educational Development. v. 30, sn, p. 359-368. 2010. doi:10.1016/j.ijedudev.2009.11.011

6. BLANHESPOOR, B., DASGUPTA, S., LAPLANTE, B., WHELER, D. Adaptation to climate extremes in developing countries: the role of education. Policy Research Working. The World Bank. 2010. Disponível em: <http://papers.ssrn.com/sol3/papers.cfm?abstract_id=1628532>. Acesso em 03 de Out. 2015.

7. CARAMELLO, G. W., STRIEDER, R. Elementos para inserir as questões ambientais em aulas de física: da prática baseada em temas à complexificação do conhecimento. Pesquisa em Educação Ambiental. v. 6, n. 2, p. 101-117. 2011. Disponível em: http://www.revis tas.usp.br/pea/ article/view/55927/59313. Acesso em: 18 jul. 2015.

8. CBD - Global Biodiversity Outlook 4. EUA. 2014. Disponível em: <https://www.cbd.int/gbo/ gbo4/publication/gbo4-en-hr.pdf>. Acesso em: 24 set. 2014.

9. CHAMBERS, D. Sustainable development: the response from education. Australian country report. Melbourne Graduate School of Education, Australia. 2009. 359 p.

10. CORREIA, P. R. M., VALLE, B. X., DAZZANI, M., MALACHIAS, E. I. The importance of scientific literacy in fostering education for sustainability: Theoretical considerations and preliminary findings from a Brazilian experience. Journal of Cleaner Production. v. 18, s.n., p. 678-685. 2010. doi:10.1016/j.jclepro.2009.09.011

11. FERNANDESSILVA, C.M.L. Mudanças climáticas e ambientais: Contextos educacionais e históricos. Natal: IFRN, 2015. 327 p.

12. GADOTTI, M. Educar para a sustentabilidade: uma contribuição à década da educação para o desenvolvimento sustentável. São Paulo: Editora e Livraria Instituto Paulo Freire. 2008. 69p.

13. GOWDY, J. M. Behavioral economics and climate change policy. Journal of Economic Behavior \& Organization. v. 68, n. 3, p. 632-644. 2008. doi:10.1016/j.jebo.2008.06.011 
14. HAN, Q. Education for Sustainable Development and Climate Change Education in China. Journal of Education for Sustainable Development. v. 9, n. 1, p. 62-77. 2015. doi:10.1177/0973408215569114

15. HILLMAN, M., FAWCETT, T., RAJAN, S.C. The Suicidal Planet: How to Prevent Global Climate Catastrophe. New York: Thomas Dunne Books, 2007. 304 p.

16. IPCC. Climate change 2014: impacts, adaptation, and vulnerability. EUA, 2014. Disponível em:<https://www.ipcc.ch/pdf/assessment-report/ar5/wg2/WGIIAR5-

FrontMatterA_FINAL.pdf>. Acesso em: 12 dez. 2014.

17. IPEA. Mudança do Clima no Brasil: aspectos econômicos, sociais e regulatórios. Brasília, 2011. Disponível em: <http://www.ipea.gov.br/portal/images/stories/PDFs/livros/livros/ livro_ mudancadoclima_port.pdf>. Acesso em: 15 dez. 2014.

18. JACOBI, P. R., GUERRA, A. F., SULAIMAN, S. N., NEPUCEMO, T. Mudanças climáticas globais: a resposta da educação. Revista Brasileira de Educação. v. 16, n. 46, p. 35-148. 2011. Disponível em: <http://www.revistas.usp.br/pea/article/view/55927/59313>. Acesso em: 12 dez. 2014.

19. JACOBI, P. R., TRISTÃO, M., FRANCO, M. I. G. C. A função social da educação ambiental: Nas práticas colaborativas participação e engajamento. Caderno Cede. v. 29, n. 77, p. 63-79, 2009.

20. KING, E., ANDREW, M. Engendering Development. World Bank Policy Research Report. January. 2001

21. LAESS $\phi E$ J., SCHANACK, K., BREITING, S., ROLLS, S. Climate Change and Sustainable Development: The Response from Education -- Cross-National Report. Copenhagen: International Alliance of Leading Education Institutes (IALEI), 2009. Disponível em: <http://edu.au.dk/fileadmin/www.dpu.dk/viden/temaeraaa/klimaogmiljoepaedagogik/forsk ning_miljoe-og-sundhedspaedagogik_klimakonference-

2009_20091210145855_dpu_recommendations.pdf>. Acesso em: 15 nov. 2015.

22. LEFF, H. Racionalidade Ambiental: a reapropriação social da natureza. Rio de Janeiro: Civilização Brasileira, 2006. 556 p.

23. LIMA, G. F. C. Educação ambiental e mudança climática: convivendo em contextos de incerteza e complexidade. Ambiente \& Educação. v. 18, n. 1, p. 91-112. 2013. Disponível em: <http://www.seer.furg.br/ambeduc/article/view/2623/2404>. Acesso em: 25 out. 2015.

24. LIMA, G. F. C., LAYRARGUES, P. P. Mudanças climáticas, educação e meio ambiente: para além do Conservadorismo Dinâmico. Educar em Revista. Edição Especial v. 3, p. 73-88. 2014. Doi: 10.1590/0104-4060.38108

25. MARUYANA, S. Aquecimento global? São Paulo: Oficina de textos, 2009.

26. MEADOWS, D. H. Harvesting one hundredfold key concepts and case studies environmental education. EUA: United Nations Environment Programme, 1989. 63 p.

27. MOCHIZOKI, Y., BRYAN, A. Climate Change Education in the Context of Education for Sustainable Development: Rationale and Principles. Journal of Education for Sustainable Delopment. v. 9, n. 1, p. 4-26. 2015. doi: 10.1177/0973408215569109

28. MOLION, L. C. B. Mitos do aquecimento global. Plenariun. v. 5, n. 5: Brasília: Biblioteca Digital da Câmara dos Deputados, 2008. 
29. NAZIR, J., PEDDRETTI, E., WALLACE, J., MONTEMURRO, D., INWOOD, H. Climate Change and Sustainable Development: The Response from Education. The Canadian Perspective. Centre for Science Mathematics and Technology Education. Ontario. International Alliance of Leading Education Institutes (IALEI). 2009. Disponível em: https:<//www.oise.utoronto.ca/ese/User Files/File/eseinpractice_file/IAELI\%200ISE\%20report\%202009.pdf>. Acesso em: 12 ago. 2015.

30. PCN+. Ministério da Educação. Brasília, 2002. Disponível em: <http://portal.mec.gov.br/se cretaria-de-educacao-basica/destaques?id=12598: publicacoes>. Acesso em: 10 out. 2014.

31. SOBRAL, F. F. Educação para a competitividade ou para a cidadania social? São Paulo em perspectiva. v. 14, n. 1, p. 3-11. 2000. Disponível em: http://dx.doi.org/10.1590/S010288392000000100002

32. STERN, N. The Economics of Climate Change: The Stern Review. Cambridge University Press, Cambridge, 2007. 662 p.

33. UNEP. Here and now! Education for sustainable consumption: Recommendations and guidelines. Paris, 2010.

34. UNESCO. Década da Educação das Nações Unidas para um Desenvolvimento Sustentável, 2005-2014: documento final do esquema internacional de implementação. Brasil, 2005. 113 p.

35. Mudança climática em sala de aula: curso da UNESCO para professores secundários (fundamental II e ensino médio) sobre educação em mudança climática e desenvolvimento sustentável (EMCDS) / David Selby e Fumiyo Kagawa. Brasília: 2014a. 374 p.

36. Climate change education for sustainable development (CESD). Nepal Country Programme. 2014b. 12 p.

37. Asia and Pacific Regional Bureau for Education. Bangkok. Thailand. 2012.

38. WWF. Relatório planeta vivo. Sumário. Brasil. 2014. Disponível em: <hc6yl9qzo4.cloud front.net/downloads/sumario_executivo_planeta_vivo_2014.pdf>. Acesso em: 25 ago. 2014. $30 \mathrm{p}$.

39. WEBSTER, M.; GINNETTI, J.; WALKER, P.; COPPARD, D.; KENT, R. The humanitarian costs of climate change. Feinstein International Center. 2009. Disponível em: <http://www.unis dr.org/files/8058_FeinsteinTuftsclimatechange.pdf>. Acesso em: 17 ago. 2015. 